\title{
ADAPTATION IN MULTI-SATELLITE CONSTELLATION COOPERATION
}

Chengyu Cao

University of Connecticut

Department of Mechanical Engineering

191 Auditorium Road, Unit 3139

Storrs, CT 06269

1 Aug 2014

Final Report

APPROVED FOR PUBLIC RELEASE; DISTRIBUTION IS UNLIMITED.

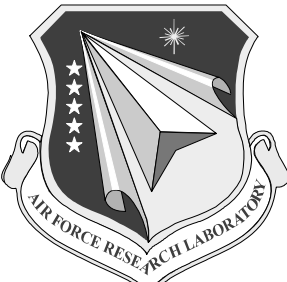

AIR FORCE RESEARCH LABORATORY Space Vehicles Directorate 3550 Aberdeen Ave SE AIR FORCE MATERIEL COMMAND KIRTLAND AIR FORCE BASE, NM 87117-5776 


\section{DTIC COPY NOTICE AND SIGNATURE PAGE}

Using Government drawings, specifications, or other data included in this document for any purpose other than Government procurement does not in any way obligate the U.S. Government. The fact that the Government formulated or supplied the drawings, specifications, or other data does not license the holder or any other person or corporation; or convey any rights or permission to manufacture, use, or sell any patented invention that may relate to them.

This report is the result of contracted fundamental research deemed exempt from public affairs security and policy review in accordance with SAF/AQR memorandum dated 10 Dec 08 and AFRL/CA policy clarification memorandum dated 16 Jan 09. This report is available to the general public, including foreign nationals. Copies may be obtained from the Defense Technical Information Center (DTIC) (http://www.dtic.mil).

Qualified requestors may obtain copies of this report from the Defense Technical Information Center (DTIC) (http://www.dtic.mil).

\section{AFRL-RV-PS-TR-2014-0113 HAS BEEN REVIEWED AND IS APPROVED FOR PUBLICATION IN ACCORDANCE WITH ASSIGNED DISTRIBUTION STATEMENT.}

//SIGNED//

KHANH PHAM

Program Manager
//SIGNED//

PAUL HAUSGEN

Technical Advisor, Spacecraft Component Technology Branch

//SIGNED//

BENJAMIN M. COOK, Lt Col, USAF

Deputy Chief, Spacecraft Technology Division

Space Vehicles Directorate

This report is published in the interest of scientific and technical information exchange, and its publication does not constitute the Government's approval or disapproval of its ideas or findings. 


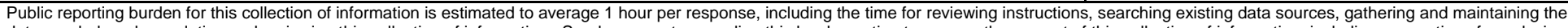

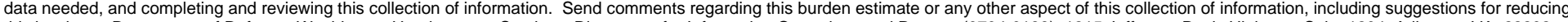

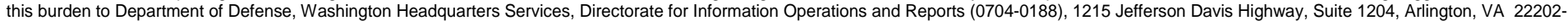

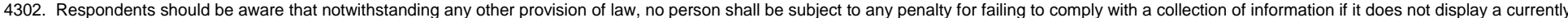
valid OMB control number. PLEASE DO NOT RETURN YOUR FORM TO THE ABOVE ADDRESS.
1. REPORT DATE (DD-MM-YY)
01-08-2014
2. REPORT TYPE
Final Report

4. TITLE AND SUBTITLE

Adaptation in Multi-Satellite Constellation Cooperation

3. DATES COVERED (From - To)

26 Apr 2013 - 17 Jul 2014

5a. CONTRACT NUMBER

FA9453-13-1-0287

5b. GRANT NUMBER

5c. PROGRAM ELEMENT NUMBER

61102F

5d. PROJECT NUMBER

3003

5e. TASK NUMBER

PPM00015448

5f. WORK UNIT NUMBER

EF010907

8. PERFORMING ORGANIZATION REPORT NUMBER

University of Connecticut

Department of Mechanical Engineering

191 Auditorium Road, Unit 3139

Storrs, CT 06269

\section{SPONSORING I MONITORING AGENCY NAME(S) AND ADDRESS(ES)}

Air Force Research Laboratory

Space Vehicles Directorate

3550 Aberdeen Ave., SE

Kirtland AFB, NM 87117-5776

\section{DISTRIBUTION I AVAILABILITY STATEMENT}

Approved for public release; distribution is unlimited.

\section{SUPPLEMENTARY NOTES}

\section{ABSTRACT}

This report details a method of determining the optimal reference trajectory for a controlled agent. The reference trajectory is chosen assuming that the system begins in steady state and the objective is to minimize control effort. The report includes the motivation for this design, a derivation of the algorithm, and simulation results. Based on the trajectory optimization of a single agent, distributed adaptation will be applied for a multi-agent network, e.g. satellite constellations.

\section{SUBJECT TERMS}

Autonomous space systems, High fidelity satellite simulator, multi-objective optimization

\begin{tabular}{|c|c|c|c|c|c|}
\hline \multicolumn{3}{|c|}{ 16. SECURITY CLASSIFICATION OF: } & \multirow{2}{*}{$\begin{array}{l}\text { 17. LIMITATION } \\
\text { OF ABSTRACT } \\
\text { Unlimited }\end{array}$} & \multirow{2}{*}{$\begin{array}{l}\text { 18. NUMBER } \\
\text { OF PAGES } \\
16\end{array}$} & \multirow{2}{*}{$\begin{array}{l}\text { 19a. NAME OF RESPONSIBLE PERSON } \\
\text { Khanh Pham } \\
\text { 19b. TELEPHONE NUMBER (include area } \\
\text { code) }\end{array}$} \\
\hline $\begin{array}{l}\text { a. REPORT } \\
\text { Unclassified }\end{array}$ & $\begin{array}{l}\text { b. ABSTRACT } \\
\text { Unclassified }\end{array}$ & $\begin{array}{l}\text { c. THIS PAGE } \\
\text { Unclassified }\end{array}$ & & & \\
\hline
\end{tabular}


(This page intentionally left blank)

Approved for public release; distribution is unlimited. 


\section{TABLE OF CONTENTS}

Section

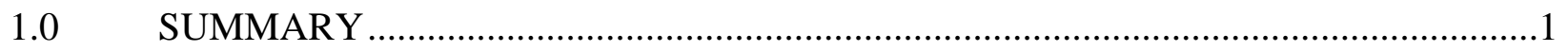

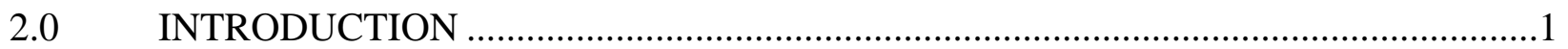

3.0 METHODS, ASSUMPTIONS, AND PROCEDURES ...................................................

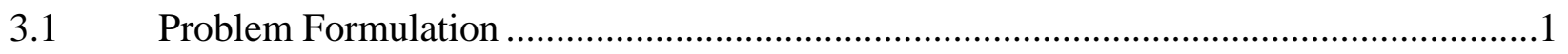

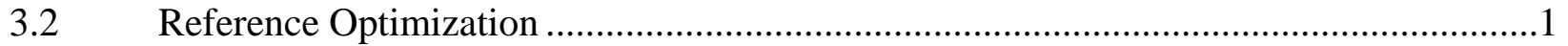

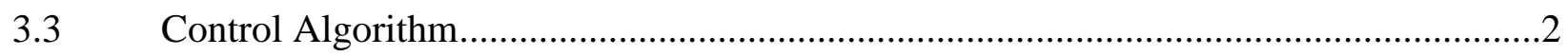

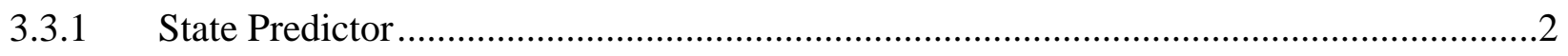

3.3.2 Adaptive Law ....................................................................................................

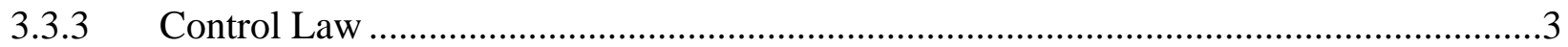

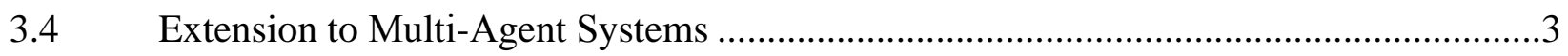

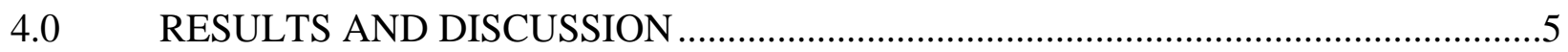

5.0 CONCLUSIONS AND RECOMMENDATIONS.......................................................

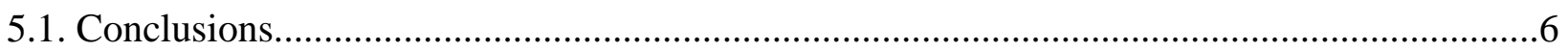

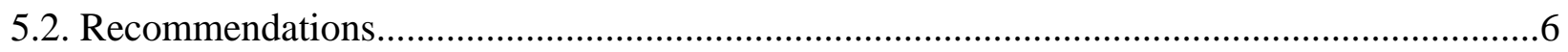

LIST OF SYMBOLS, ABBREVIATIONS, AND ACRONYMS............................................. 
(This page intentionally left blank)

Approved for public release; distribution is unlimited. 


\subsection{SUMMARY}

This report details a method of determining the optimal reference trajectory for a controlled agent. The reference trajectory is chosen assuming that the system begins in steady state and the objective is to minimize control effort. The report includes the motivation for this design, a derivation of the algorithm, and simulation results. Based on the trajectory optimization of a single agent, distributed adaptation can be applied for a multi-agent network, e.g. satellite constellations.

\subsection{INTRODUCTION}

In many control applications, such as satellite orbit stabilization, fuel savings are an important consideration. Furthermore, every real system is subject to uncertainties and disturbances. In the presence of uncertainties, estimation is necessary to solve this optimization problem. An adaptive control architecture, named L1 adaptive control, provides a framework where uncertainty estimates can be used to solve the optimization problem if we consider a system at steady state. L1 gain of a linear time-invariant (LTI) system is defined as the L1 norm of its impulse signal. L1 adaptive control got its name because its stability condition is usually expressed using L1 gains.

\subsection{METHODS, ASSUMPTIONS, AND PROCEDURES}

\subsection{Problem Formulation}

Consider a single-input single output system with full state feedback,

$$
\begin{aligned}
& \dot{x}(t)=A_{K} x(t)+B u_{K}(t)+\sigma(x, t) \\
& x(0)=x_{0}=0
\end{aligned}
$$

For any controllable $A_{K}, B$, there exists $K \in \mathbf{R}^{n}$ such that a nominal control signal, $-K^{T} x(t)$ stabilizes the system, i.e. $A_{K}-B K^{T}$ is Hurwitz. We can then represent the system in (1) as

$$
\dot{x}(t)=A x(t)+B u(t)+\sigma(x, t)
$$

where $\mathrm{A}=\mathrm{A}_{\mathrm{K}}-\mathrm{BK}^{\mathrm{T}}$ and $\mathrm{u}(\mathrm{t})=\mathrm{u}_{\mathrm{K}}(\mathrm{t})+\mathrm{K}^{\mathrm{T}} \mathrm{x}(\mathrm{t})$. Because $\sigma(\mathrm{x}, \mathrm{t})$ is bounded, this system is still controllable even in the presence of these uncertainties.

The control objective is for $\mathrm{x}(\mathrm{t})$ to maintain a give constraint, $\mathrm{g}(\mathrm{x})=0$, while simultaneously minimizing $\|\mathrm{u}(\mathrm{t})\|^{2}$.

\subsection{Reference Optimization}

To achieve the control objective, we determine an optimal reference point at every timeinstant. The time-history of these reference points constitutes a reference signal, $r(t)$, for the system to track. To determine $\mathrm{r}(\mathrm{t})$, we first assume that the system is in steady-state and tracking $r(t)$. This allows to rewrite (3) as 


$$
0=\operatorname{Ar}(\mathrm{t})+\mathrm{Bu}(\mathrm{t})+\sigma(\mathrm{r}, \mathrm{t})
$$

Solving (4) for $\mathrm{u}(\mathrm{t})$ yields

$$
u(t)=-B^{-1}(\operatorname{Ar}(t)+\sigma(r, t))
$$

and

$\|\mathrm{u}(\mathrm{t})\|^{2}=\mathrm{u}(\mathrm{t})^{\mathrm{T}} \mathrm{u}(\mathrm{t})=(\operatorname{Ar}(\mathrm{t})+\sigma(\mathrm{r}, \mathrm{t}))^{\mathrm{T}}\left(\mathrm{B}^{-1}\right)^{\mathrm{T}} \mathrm{B}^{-1}(\operatorname{Ar}(\mathrm{t})+\sigma(\mathrm{r}, \mathrm{t}))$

We can now formulate the optimization problem as

$\min _{r(t)} f(r(t))=(\operatorname{Ar}(t)+\sigma(r, t))^{T}\left(B^{-1}\right)^{T} B^{-1}(\operatorname{Ar}(t)+\sigma(r, t))$

subject to $\quad \mathrm{g}(\mathrm{r}(\mathrm{t}))=0$

To solve this problem, we define the Lagrangian,

$\mathrm{L}(\mathrm{r}, \mathrm{v})=\mathrm{f}(\mathrm{r}(\mathrm{t}))+\mathrm{vg}(\mathrm{r}(\mathrm{t}))$

The optimal $r(t)$ then satisfies

$\nabla L(r, v)=\left[\begin{array}{c}2 A^{T}\left(B^{-1}\right)^{T} B^{-1}(\operatorname{Ar}(t)+\sigma(r, t))+v \frac{d g}{d r} \\ g(r(t))\end{array}\right]=0$

The remaining issue is that $\sigma(\mathrm{r}, \mathrm{t})$ is unknown. To account for this, we replace $\sigma(\mathrm{r}, \mathrm{t})$ with an adaptive estimate, $\widehat{\sigma}(t)$. Then we choose $r(t)$ such that

$\nabla L(r, v)=\left[\begin{array}{c}2 A^{T}\left(B^{-1}\right)^{T} B^{-1}(\operatorname{Ar}(t)+\widehat{\sigma}(r, t))+v \frac{d g}{d r} \\ g(r(t))\end{array}\right]=0$

is satisfied. The adaptive law that generates $\widehat{\sigma}(\mathrm{t})$ will be derived in the following section.

\subsection{Control Algorithm}

The control algorithm consists of a state predictor, adaptive law, and control law.

3.3.1 State Predictor. The state predictor is a dynamic system designed to mimic the structure of (3),

$\dot{\hat{x}}(t)=A \hat{x}(t)+B u(t)+\widehat{\sigma}(t)$

3.3.2 Adaptive Law. The adaptive law is designed to drive the error between the predicted state and the real state to zero. To do this, we look at the dynamics of the prediction error, $\tilde{x}(t)=\hat{x}(t)-x(t)$. This yields

Approved for public release; distribution is unlimited. 
$\dot{\tilde{x}}(t)=A \tilde{x}(t)+\widehat{\sigma}(t)-\sigma(x, t)$

The solution of $(13)$ at $t=(i+1) T$ is

$\tilde{x}((i+1) T)=e^{A T} \tilde{x}(i T)+\int_{0}^{T} e^{A(T-\tau)} \widehat{\sigma}(i T+\tau) d \tau-\int_{0}^{T} e^{A(T-\tau)} \sigma(x, i T+\tau) d \tau$

We choose $\widehat{\sigma}(\mathrm{t})=\widehat{\sigma}(\mathrm{iT})$ for $\mathrm{t} \in[\mathrm{iT},(\mathrm{i}+1) \mathrm{T})$. This allows us to take $\widehat{\sigma}$ out of the integral in (14). Since $\sigma(x, t)$ is unknown, we neglect its effects for the selection of $\widehat{\sigma}(\mathrm{t})$. So to find $\widehat{\sigma}(\mathrm{iT})$, we neglect the third term on the right-hand side of $(14)$ and set $\tilde{\mathrm{x}}((\mathrm{i}+1) \mathrm{T})=0$. This yields

$\widehat{\sigma}(\mathrm{iT})=-\left[\int_{0}^{\mathrm{T}} \mathrm{e}^{\mathrm{A}(\mathrm{T}-\tau)} \mathrm{d} \tau\right]^{-1} \mathrm{e}^{\mathrm{AT}} \tilde{\mathrm{x}}(\mathrm{iT})$

3.3.3 Control Law. The control law is designed to drive $\hat{x}(t)$ to $r(t)$. This combines with adaptive law drives $x(t)$ to $r(t)$. The first part of the control law is designed assuming $\widehat{\sigma}(t)=0$. Then we simply use the steady-state gain,

$\mathrm{u}_{1}(\mathrm{t})=-\left[\mathrm{A}^{-1} \mathrm{~B}\right]^{-1} \mathrm{r}(\mathrm{t})$

The other component of the control law serves to cancel the effects of $\widehat{\sigma}(t)$. To do this, we simply choose the opposite of $\widehat{\sigma}(t)$ and apply a low-pass filter to compensate for the effects of the high-gain feedback adaptive law,

$\mathrm{u}_{2}(\mathrm{t})=-\mathrm{C}(\mathrm{s}) \widehat{\sigma}(\mathrm{t})$

The total control law is

$\mathrm{u}(\mathrm{t})=\mathrm{u}_{1}(\mathrm{t})+\mathrm{u}_{2}(\mathrm{t})$

\subsection{Extension to Multi-Agent Systems}

A satellite constellation is a group of artificial satellites that work together to fulfill some common objectives. Through coordination, the constellation members can fulfill cooperative tasks that a single satellite could not. For example, coordinated ground coverage can be achieved such that constellation members overlap well in coverage and complement rather than interfere with each other. A second example is to coordinate multiple satellites with different onboard sensors to extract additional information about a sensed target using sensor fusion. Maintaining reliable communication links between satellites and ground stations is another critical requirement for many satellite constellations.

Consider a constellation of three satellites. The dynamics of each satellite are described as follows [1]. The reference coordinate system has the $\mathrm{x}$-axis pointing toward the vernal equinox and the z-axis pointing upwards. The right-hand convention defines the y-axis, completing the triad. We assume that the earth is spherical and uniform. The satellite's position in the earthcentered inertial coordinates should satisfy the equation of motion, 
$\ddot{\vec{r}}(t)=-\frac{\mu}{r^{3}(t)} \vec{r}(t)+f(t)+u(t)$

where $\mu \equiv 398,600 \mathrm{~m}^{3} / \mathrm{s}, r \equiv\|\vec{r}\|$ is the distance between the satellite and the center of the earth. The radial component of the satellite's velocity is given by $v_{r} \equiv \frac{\vec{v} \cdot \vec{r}}{r}$, and the satellite's specific angular momentum is given by $\vec{h}=\vec{r} \times \vec{v}$. The orbit's inclination is given by $i \equiv \cos ^{-1}\left(\frac{h_{z}}{h}\right)$, and its eccentricity by

$\vec{e} \equiv \frac{1}{\mu}\left[\left(v^{2}-\frac{\mu}{r}\right) \vec{r}-r v_{r} \vec{v}\right]$

The longitude of the ascending node is given by

$\Omega \equiv\left\{\begin{array}{cc}\cos ^{-1}\left(n_{x}\right) & n_{y} \geq 0 \\ 2 \pi-\cos ^{-1}\left(n_{x}\right) & n_{y}<0\end{array}\right.$

and the argument of perigee is given by

$\omega \equiv\left\{\begin{array}{cc}\cos ^{-1}\left(\frac{\vec{n} \cdot \vec{e}}{e}\right) & e_{z}>0 \\ 2 \pi-\cos ^{-1}\left(\frac{\vec{n} \cdot \vec{e}}{e}\right) & e_{z}<0\end{array}\right.$

with the convention that $\omega=\cos ^{-1}\left(\frac{e_{x}}{e}\right)$ for an equatorial orbit. The true anomaly is given by

$v \equiv\left\{\begin{array}{cc}\cos ^{-1}\left(\frac{\vec{e} \cdot \vec{r}}{e r}\right) & v_{r}>0 \\ 2 \pi-\cos ^{-1}\left(\frac{\vec{e} \cdot \vec{r}}{e r}\right) & v_{r}<0\end{array}\right.$

with the convention that $v=\cos ^{-1}\left(\frac{r_{x}}{r}\right)$ for a circular orbit. The eccentric anomaly is given by

$E=\cos ^{-1}\left(\frac{1-r / a}{e}\right)$

where $a=\frac{2}{\frac{2}{r}-\frac{v^{2}}{\mu}}$. The mean anomaly is given by $M=E-e \sin E$, and the orbit period is given by $T=2 \pi \sqrt{\frac{a^{3}}{\mu}}$. The position of the satellite is fully defined by the parameter set $\{i, \Omega, \omega, T, e, v\}$. The angles $\{i, \Omega, \omega\}$ transform the inertial frame to the orbital frame, $T$ and $e$ define the size and shape of the orbit, and $v$ defines the satellite's position.

For the purposes of this project, we will consider two types of disturbances that each satellite may be subjected to, namely atmospheric drag and solar radiation pressure. The acceleration due to drag can be modeled as

$f_{D}=-\frac{1}{2} C_{D} \frac{A_{C s} \rho v_{r}^{2}}{m v} \vec{v}$

The acceleration due to the solar radiation pressure is modeled as

$f_{R}=-P_{E}(1+\epsilon) \frac{A_{c s} \vec{r}_{S}}{m\left\|\vec{r}_{S}\right\|^{3}} \times 1 \mathrm{AU}^{2}$

The sum of the disturbances acting on each satellite in (19) is

$f(t)=f_{D}+f_{R}$

The dynamics of the total constellation can be expressed as

$\dot{x}_{i}(t)=A_{i} x_{i}(t)+b_{i} u_{i}(t)+\sigma_{i}(t), \quad i=1,2,3$

$$
y_{i j}(t)=c_{i j} x_{i}(t), \quad j=1,2,3
$$

where 


$$
\begin{aligned}
& x_{1}=\left[\begin{array}{llllll}
r_{x 1} & v_{x 1} & r_{x 2} & v_{x 2} & r_{x 3} & v_{x 3}
\end{array}\right]^{\top} \\
& x_{2}=\left[\begin{array}{llllll}
r_{y 1} & v_{y 1} & r_{y 2} & v_{y 2} & r_{y 3} & v_{y 3}
\end{array}\right]^{\top} \\
& x_{3}=\left[\begin{array}{llllll}
r_{z 1} & v_{z 1} & r_{z 2} & v_{z 2} & r_{z 3} & v_{z 3}
\end{array}\right]^{\top} \\
& \text { and } \\
& c_{i 1}=\left[\begin{array}{llllll}
1 & 0 & 0 & 0 & 0 & 0
\end{array}\right] \\
& c_{i 2}=\left[\begin{array}{llllll}
0 & 0 & 1 & 0 & 0 & 0
\end{array}\right] \\
& c_{i 3}=\left[\begin{array}{llllll}
0 & 0 & 0 & 0 & 0 & 1
\end{array}\right] \\
& \text { for all } i .
\end{aligned}
$$

We do not model the actuators used to generate the thrust for each satellite. Here, we will simply assume that any thrust less than a given limit can be obtained by an inner-loop controller,

$u_{i j} \leq u_{\max }$

In the interest of fuel conservation, each satellite is only controlled when it leaves a defined error box about the reference position. The error box is larger when the satellite is entering it than when leaving it. We have

$$
u_{i j}=\left\{\begin{array}{c}
u_{i j, n o m} \text { if }\left|R_{i j}-y_{i j}\right|>E_{i n} \text { and } \frac{d}{d t}\left|R_{i j}-y_{i j}\right| \leq 0 \\
u_{i j, n o m} \quad \text { if }\left|R_{i j}-y_{i j}\right|>E_{i n} \text { and } \frac{d}{d t}\left|R_{i j}-y_{i j}\right|>0 \\
0 \quad \text { if }\left|R_{i j}-y_{i j}\right| \leq E_{i n} \text { and } \frac{d}{d t}\left|R_{i j}-y_{i j}\right|<0 \\
0 \quad \text { if }\left|R_{i j}-y_{i j}\right|<E_{i n} \text { and } \frac{d}{d t}\left|R_{i j}-y_{i j}\right| \geq 0
\end{array}\right.
$$

Finally, the control objective is for all three satellites to maintain an equal distribution around the earth at a given constant altitude and in the same orbital plane.

Since all individual satellite faces uncertainties and disturbances described above, same algorithm can be implemented as distributed controllers for individual satellite in a satellite constellation. The adaptive algorithm for a single agent described in 3.0-3.3 can be implemented as decentralized controller. The only modification is how the desired reference trajectories will be derived. Eq. (8)-(9) will be revised to an optimization problem in the multi-agent framework. In addition to fuel cost, cooperative objective will also be considered.

\subsection{RESULTS AND DISCUSSION}

Figure 1 shows simulation results for a system with the parameters

$$
A=\left[\begin{array}{cc}
0 & 10 \\
-1 & -\sqrt{2}
\end{array}\right], B=\left[\begin{array}{ll}
1 & 1 \\
0 & 1
\end{array}\right], T=0.0001, C(s)=\frac{100}{s+100} \text {, and } g(x)=x_{1}+x_{2}+50
$$




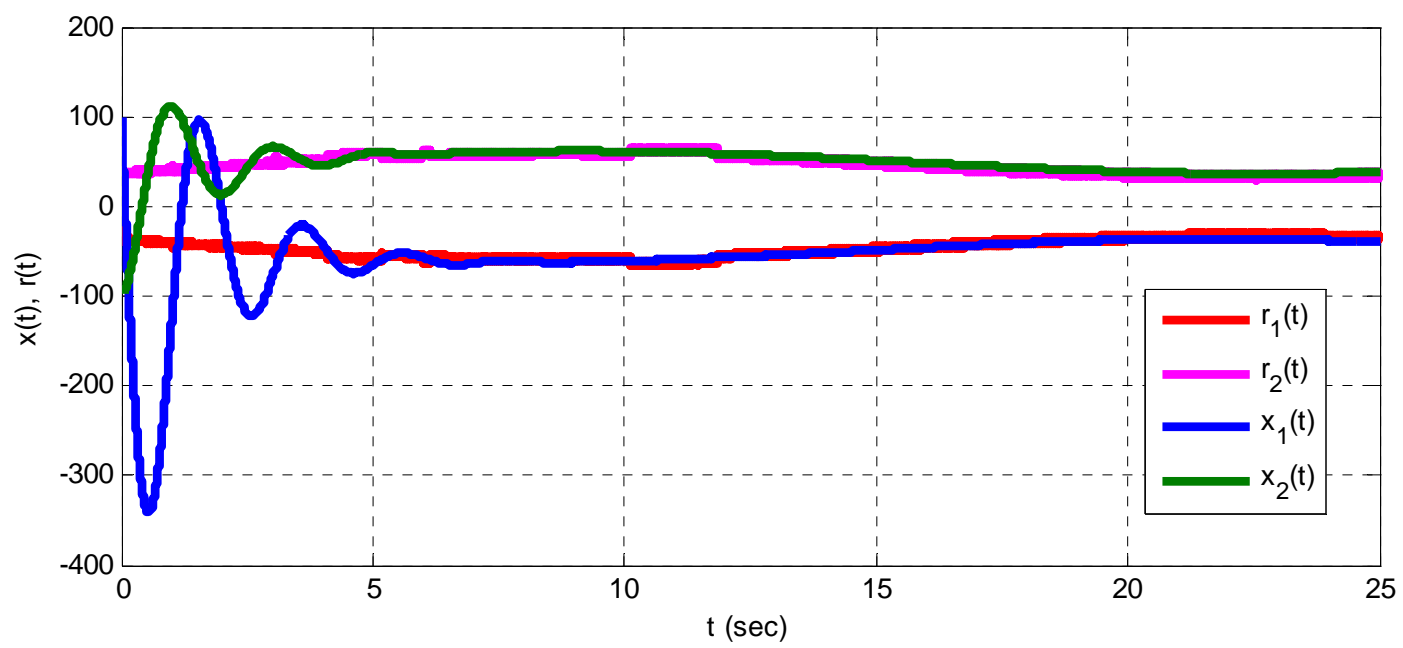

Figure 1. Simulation Results

The simulation results show good tracking performance while $r(t)$ varies according to the reference optimization algorithm. Extension to multi-agent systems with its application to satellite constellation is under further investigation.

\subsection{CONCLUSIONS AND RECOMMENDATIONS}

5.1. Conclusions. This report presents a new method for reference trajectory optimization for use with the L1 adaptive control architecture. The L1 formulation specifically lends itself to solving the optimization problem if we assume the system is in steady state. Since adaptive uncertainty estimates are available, we can substitute the estimates into the optimization problem in order to find the solution for a system with unknown disturbances and modelling uncertainty. The simulation results show that the controller is able to track satisfactorily whilst updating the reference signal according to the reference optimization algorithm. The method can be further extended to multi-agent systems. In a satellite constellation, reference trajectory can be optimized in a distributed manner using multi-objective optimization. At the same time, each single satellite can follow optimized reference trajectories individually.

5.2. Recommendations. This result lends itself to application in a multi-agent cooperative control setting and specifically the problem of satellite constellation control. In this framework, the problem formulation is similar to what has been presented here, except the system state is composed of state variables from multiple independent vehicles, each with their own decentralized controllers. Then the control input is the thrust of each satellite, and minimizing it is equivalent to minimizing fuel usage of the constellation.

In the future extension to satellite constellation control, models would be adopted for gravitational forces, aerodynamic drag, and solar radiation pressure. Each member of the constellation would operate in one of two modes: continuous low-thrust or impulsive high-thrust. The continuous low-thrust mode is used when the satellite is on or very near to the desired orbit or trajectory. If the satellite drifts past a threshold distance away from the desired path, the impulsive high-thrust mode is switched on. The switching logic between these modes may 
introduce additional considerations for theoretical algorithm development. Overall, the reference optimization controller provides a rich basis for investigating applications relevant to AFRL's goals. 


\section{LIST OF SYMBOLS, ABBREVIATIONS, AND ACRONYMS}

L1 Adaptive control architecture

LTI Linear time-invariant

Approved for public release; distribution is unlimited. 


\section{DISTRIBUTION LIST}

DTIC/OCP

8725 John J. Kingman Rd, Suite 0944

Ft Belvoir, VA 22060-6218

$1 \mathrm{cy}$

AFRL/RVIL

Kirtland AFB, NM 87117-5776 2 cys

Official Record Copy

AFRL/RVSV/Khanh Pham 1 cy

Approved for public release; distribution is unlimited. 
(This page intentionally left blank)

Approved for public release; distribution is unlimited. 